\title{
Information-wave processes in social education activity of a contemporary university
}

\author{
Nikolay N. Kiselev, ${ }^{1, *}$ \\ ${ }^{1}$ NSPU, Department of Pedagogy and Psychology, Institute of History, Humanitarian and Social Education, Novosibirsk, Russia
}

\begin{abstract}
The paper analyzes the approaches to the problem of information-wave processes in the social education activity of a contemporary university. The possibilities to apply the wave approach in the social education activity of a university by focusing on such social education technology as "interactions wave" are considered. The paper presents a step-by-step realization of this technology in the social education activity of a university.
\end{abstract}

In modern eco-ethics the human interaction, as an exchange of psychic energy, is called the information and energy exchange. It means both conscious and intuitive channels of perception.

Physics knows four types of fundamental interactions: gravitational, electromagnetic and two quantum interactions (strong and weak). However, they may not explain the consciousness phenomenon. Hypotheses put forth in the $20^{\text {th }}$ century by a number of researchers suggest the possibility of the fifth type of fundamental interaction. V.N. Volchenko studies these hypotheses in his research. Let us mention just one example - N.A. Kozyrev's psychon model. He explains the work of the neuronal network in the human brain where psychons (superlight gas), which possess a significant "associated wave" length, perceive the information flow earlier than its own cells.

It is interesting to look at the wave mechanism within the aspect of information spread. Wave processes reveal such primary characteristics as diffraction and interference. Diffraction (decomposition) is the round-about flow of the obstacle, which leads to maximums and minimums. This phenomenon is observed during intentional distortion of information, spread of gossip or when information is passed to an individual (or group) that modifies or devalues the information.

Interference ("inter" means "between") is superposition of waves, their amplification in some points of space and decay in others depending on the interfering wave length difference. Such a process may be detected when the same kind of information is transformed through different channels ("phases"): mass media, lectures, posters, films, etc.

Both the first and second wave processes may entail both positive and negative attitude of an individual or group to the incoming information as the attitude is primarily determined by emotions. In his information theory of emotions P.B. Simonov showed that emotions correlate with the level of information obtained by an individual: necessary and insufficient. The greater is the lack of the necessary information, the higher is the level of obtained information (compared to the necessary information) and the higher is the chance of experiencing positive emotions.

B.F. Porshnev introduced the categories of "Us" and "Them" to characterize individual (and group) attitudes to the source of information. "Us" is seen as the trust filter. Information that comes from "Us" is perceived as true unlike the information coming from "Them" [4].

In terms of a university social education environment, creating the "We" atmosphere (our university, our traditions) is the key requirement in shaping positive settings for the coming information. In this atmosphere it is rather easy to apply both mechanisms of diffraction (creating "obstacles") and interference (amplification) of information waves.

Rectilinear (frontal) information produces no pedagogical impact. To contrast it, we may apply the "roundabout" (diffraction) method, or game method. The acknowledged leaders of modern gaming pedagogy in organizing children's summer leisure, S.A. Shmakov and O.S. Gazman, used gaming "diffraction filters" to the maximum. During a game, children do not perceive themselves to be objects of social education. Instead, they act as subjects of activity in various roles: city planners in the "City of tradesmen", circus acrobats in the "Arena of brave and skilled people", lancers in the "Battle of Borodino", etc. The game is the best tool to disguise pedagogical implications; therefore it is the most efficient. The same mechanisms also work in the social education activity of a university. Here, there is no need to urge young people to be independent, initiative, etc. The gaming situation (in and out of the class), if sustained by an appropriate role, enables the student to be active in living through and receiving this information. While 
identifying such human subsystems as the conscious, subconscious and superconscious, P.V. Simonov stressed that learning focuses on conscious, social education - on the subconscious, and games - on the superconscious [5]. It is the latter that ensures creativity. It is important to remember L.S. Vygotsky's statement that "in play a child always behaves beyond his average age" [2].

A well-organized gaming atmosphere builds up the "Us" feeling, a special emotional field with a positive charge. If such atmosphere is not present, no playful tricks of the organizers will be trustworthy. Information wave "maximums" are reflected in consciousness as active attempts to overcome administrative bans.

In terms of the wave approach, the information process must be considered in situations of university assessment and social education processes. Assessment information sources usually include the administration, faculty and students. That is, the objects of assessment are specific individuals; assessment in itself is positive (though quite often praise is given to the same children). The situation of success as the key condition in "problem" children's correction implies imperative rationed presence of assessment information. It is important that the information should be rationed as the information maximum may awake students' suspicion that there is intentional social education influence. There is also a significant multifaceted impulse of information assessment waves: from administration to teachers and department heads, and further from teachers to student "as if" apart from the object of assessment. By obtaining positive direct and indirect information the student experiences emotional wellbeing. It especially works accompanied by A.S. Makarenko's method of the "advancement of personality".

Successful positive assessment is possible in case of a good positive psychological environment of the faculty that also initiates a healthy psychological climate within the students' community. N.N. Kiselev coined the term of "relationship wave" meaning the technology to create a certain style of interactions in the community [3].

Essentially, the technology implies that the optimistic style of life, necessary for social education, is created with special techniques through personally valuable collective interactions, which expand from the center towards the periphery and involve an increasing number of people. The "impulse" starting the "relationship wave" is the "team", a group of likeminded people located in the "center" of the collective. They often tend to be just close friends. This team may be described as an initiator in creating the university's psychological and pedagogical "Us" effect. Let us identify the technological steps:

1. Personification of "Us" in the community is dynamic: first it is the nucleus of the circle, a team of like-minded people; then, in terms of organization, follows the faculty. Without much explanation the team shows everybody the "desired" style of interaction and behavior characteristic of the nucleus and accepted by the university, namely: relaxedness, creativity, play, shared values (including the university as a value in its own right), etc. Thus, there is some sort of the "ideal" interactions system, the model of life activity, which is an extremely important idea in the pedagogy of relationships. In a very general sense, it means control over the "interaction wave" spread.

2. The next circle of interactions involves student leaders. As a rule, this circle is constantly and significantly renewed. The "Us" effect grows and expands. To "launch the wave", the demonstration of "ideal" relationships is not enough: here, as a rule, a specially and purposefully organized activity is required. This activity must be based on support of the administration and the "nucleus" of the collective both emotional and methodological.

The first level of support implies creating emotional protection for each member of faculty when administration ensures that each faculty member should feel comfortable in the university and emotionally satisfied with their work. If, due to some reason, the teacher is in an unfavorable emotional and psychological situation, it should be the concern of the department heads who are supposed to create proper conditions and find a painless way out of the crisis.

And here the first level of support, professional and methodological, is extremely important. This level provides teachers' confidence in their activity (help in mastering the basics of activity, its content, forms, specifics, etc.).

Next, the teachers' goal is to create the cohesive fellowship with students, i.e. to merge "Us" and "Them" into the wholesome "Us". Only in case of such homogeneous "Us" there develops the functioning model of "necessary" human interactions featuring a truly high social education potential. Everything contributes to this goal: both academic / research (students' readings, conferences, contests) and afterschool (adaptive camps, student leaders' gatherings, amateur contests, etc.) potentials.

So the third circle of the forming "interactions wave" involves students. Integration of the students and faculty's "Us" takes place through joint activities including collective, creative, educational and research events as well as the university traditions.

One of the most significant university traditions involves the annual key events (traditional creative and scientific activities). Giving birth to new ideas and their translation may also be considered as a part of the wave process. We may tentatively identify several steps in the creation of new ideas. On the first stage, ideas are designed by policy makers and leaders who later inform the faculty. After a number of school terms students come up with new ideas, think them over and translate them to their teachers. There is a change of wave sources. Then the generalized idea is spread all over the university by joint efforts (information wave interference). The third step comes when ideas are ripening in the students' collective with the help of student leaders (most active members). This is a new source of "wave creativity". The third step is undoubtedly the result of meaningful social education 
measures and appropriate design of information wave vectors in the social education activity of the university.

This publication was possible due to the Russian Humanitarian Science Foundation grant, Project No.15-0610447 .

\section{References}

1. V.N. Volchenko, World outlook and eco-ethics of the $21^{\text {st }}$ century ( Bauman MGTU Publishing, Moscow, 2001) [In Rus]

2. L.S. Vygotsky, Issues of Psychology 6, 62-68 (1966)

3. N.N. Kiselev, E.V. Kiseleva, Social and supplementary education in Novisibirsk Province, 2, 28-30 (2002)

4. B.F. Porshnev, Social psychology and history (Moscow, 1979)

5. P.V. Simonov, Motivated brain (Moscow, 1987) 